\title{
Overview and reflections
}

\author{
M C CHATURVEDI ${ }^{\dagger}$ and PETER ROGERS* \\ ${ }^{\dagger}$ Applied Mechanics Department, Indian Institute of Technology, Hauz Khas, New Delhi \\ 110016 \\ *Department of Environmental Engineering, Harvard University, Pierce Hall, 121, \\ Cambridge Mass. 02138 USA
}

\section{Introduction}

Modern technology is becoming increasingly large scale and powerfully pervasive. Although, in the last analysis, technology is mediated through specific projects, often these projects are part of a large-scale complex system. For instance, a number of power projects of varying types and capacities are interconnected through power grids to act as one system. Several dams and barrages on a river are interconnected through continuity of the hydrological flow. To give another example, the surface water development is interlinked with groundwater development as both serve the purpose of meeting the water demand and one has to think of conjunctive surface and ground water development. Further, since surface waters generate energy and provide irrigation, while development of groundwater sources consumes energy, conjunctive surface-groundwater-energy systems planning becomes attractive.

New technical advances are being introduced at an increasingly rapid rate leading to what has been said to be a discontinuous world. In view of the scale, pervasiveness and uncertainty of modern technology, it becomes increasingly important that its development is undertaken creatively and in a scientific manner: Secondly, in view of the relationship between technology in space and time it is necessary that a comprehensive though dynamic view of the technology be attempted. It is also equally necessary that the impacts of technology are creatively assessed and the technological choices are scientifically evaluated.

Of late, a new scientific discipline known as systems analysis has evolved through developments in the separate disciplines of engineering, economics and mathematics. Rapid developments have taken place in this science and the availability of high-speed, efficient and economical computers has contributed to its development. As the science of systems analysis has advanced over the last two decades and as the scale of modern water resources projects has grown, systems planning of water resources has been made mandatory by law in many developed countries. International agencies also emphasize systems planning. For instance, at the United Nations Water Conference held in Argentina in 1977, the need for water resources planning was promulgated as follows (UN document E/Conf. 70/29, 1977).

"Systems analysis and modelling techniques should be applied to improve efficiency and efficacy in storage operation and distribution systems. Studies should explore the possibility of effecting interbasin transfer of water and special attention should be paid to environmental impact studies ... Water managemeñt plans may be prepared by 
using systems analysis techniques and developed on the basis of already adopted indicators and criteria taking into account the economic and social evolution of the basin . . . Master plans should be formulated for countries and river basins to provide a long term perspective for planning, using such techniques as systems analysis and mathematical modelling as planning tools wherever appropriate ... ".

Systems planning of water resources is particularly important in India for a number of reasons. First the scale of development is monumental. According to the proposed targets for the Sixth Five Year Plan, irrigation at the highest level in the world, and almost five times the present level in USA, would be achieved. Second, the magnitude of the contemplated work is also very great. For instance, development of the GangaYamuna basin envisages construction of five very high dams and 22 hydroelectric runof-river schemes which have to be planned integrally. As another example, under the National Water Plan, interbasin interlinkage of several river basins is being planned. Third, while the water resources development is extremely important and critical, there are competing demands from other sectors. With water resources development accounting for almost $20 \%$ of the National Plan allocations it is necessary that the development is carried out in an efficient manner.

In contrast to the need for efficient development, the present achievements, as noted in the Sixth Five Year Plan, are not efficient. We do not mean to negate the scale of technological development or their rate of development. Irrigation works of India have been, and continue to be, some of the wonders of the world, but their technological functioning is not one of the best. If the present state continues there will be a serious problem of resource depletion and environmental degradation, both in surface water and groundwater (Chaturvedi 1976). It is, therefore, necessary that an appropriate policy and systems plan be followed. This will require integrated planning from the micro-level to the macro-national level.

Importance of systems planning has been recognized by decision makers in India. One of the present authors (MCC) was invited for the systems planning of the Ganga basin as far back as 1968 by the Indian government and a preliminary study was carried out. From the Fourth Plan onwards, the need for systems planning has been emphasized in the National Plan. The author was also invited by the Planning Commission to carry out the systems planning of Punjab. The Expert Committee of the National Committee of the International Hydrological Programme on Research and Education strongly recommended scientific development of water resources through systems analysis. But the development in real life continues to be fairly ad hoc.

The reasons for the present approach are understandable. Not many professionals are yet aware of the potential and scope of these modern approaches. The institutional constraints are such that specialisation in different activities of engineering viz research, planning, design, construction and management, of course with due interlinkage, is not developed. While in the last analysis institutional modernisation is the most important requirement for modernization of water resources development, it is necessary to develop widespread indigenous capability of systems planning amongst the professionals and academicians and demonstrate the applicability of systems analysis techniques to Indian conditions. It was in this context that the present project was undertaken and it is hoped that some contribution has been made to this end. 


\section{Systems analysis}

Systems analysis is often taken to mean mathematical modelling and it is necessary that this misunderstanding is removed. Systems analysis is a body of concepts, approaches and techniques. We shall try to give a brief introduction to systems analysis and for details reference may be made to Klir (1969), Sage (1977), Hall \& Dracup (1970), Meta Systems Inc. (1975), Biswas (1976) and Chaturvedi (1984).

Although technology has been practised since the early history of man, a new understanding of technology is gradually developing. Technology is not merely a set of constructed facilities, tools or processes, but it is a totality of activities transforming the environment. This transformation involves resources, energy or/and information according to certain technological laws. While technological activities in the context of art and science of different disciplines have to be carried out, in the last analysis technology basically results in a change of environmental state and processes. With this change there is a concomittant change in the scope of life activities. Confining this to the human system, our perceptions, values and opportunities may change. For instance, with the availability of transportation and communication systems, the concept of space and time changes. Similarly, with the availability of modern energy systems, the scope of human power and opportunities of action dramatically change. With the availability of modern production capability a new world of action is unfolded.

Modern technology is interconnected. Various elements or projects operate in the context of certain technological objectives. Even when they are differentiated in space and time they are integrated in terms of these overall objectives. These systems are organic-dynamic as they evolve over and decay with time.

Technology interacts with society in a circular manner. On the one hand technology is brought about by the capabilities of society. Technology, by providing a new environment, shapes the perceptions, opportunities and values of society. In the final analysis, technology acts as an agent of social change. There is thus another commonality of objectives, the socio-economic objectives interlinked with technological-environmental objectives.

It becomes necessary that the development and evaluation of technology be undertaken integrally as one set of activities. Technology has to be created through a sensitive understanding of technological sciences and arts and evaluated critically so that hopefully we move into a better future. There is a paradox here. With the increasing scale and the discontinuity in the development of technology, there is going to be an increasing uncertainty about opportunities and impacts. It is thus all the more necessary that we try to instill as much certainty as possible in the choice of technology and its concomittant effects. This paradox is not a contradiction, but is a continuation of the paradox of life.

The perceptions vary from individual to individual, from group to group, and furthermore are not constant over time. It thus becomes necessary that technology is evaluated through a participatory open mechanism. A new body of approaches and techniques for evaluation has also developed as will be discussed later.

Technology involves development of hardware and software, but in addition it involves development of institutional systems and motivational mechanisms. It is this set of three issues which defines the technological system and not mere hardware as was often the view of the past.

To sum up, technological projects are part of an organic-dynamic system brought 
into being for transforming environment in terms of certain techno-environmental and socio-economic objectives. The system consists, besides the software and hardware, of appropriate institutional and motivational mechanisms.

Systems analysis emphasises an approach so that technology is developed scientifically and creatively. A five-step systems approach has been developed. First, we try to identify the various issues. In that context we next try to be precise by specifying the objective and developing a set of measures to evaluate the objectives. In the third step, in the context of these objectives, various technological options are developed which in the totality of a system define the technological system. The system consists of a portfolio of projects which will have to be taken over time and space and the evolution has to be not in terms of the project, but in the totality of the system. In the fourth step we try to evaluate the various alternative technological options, and finally in the fifth step we select one of the systems in terms of quantified and non-quantified objectives.

There is a morphology in systems planning. Starting with an idea one tends to become more and more specific in a set of hierarchical evolutionary stages. In the first instance, we have the feasibility study where the techno-economic feasibility is identified so that a decision could be taken on the investment of further resources of time and of man, if deemed appropriate. In the second phase we have detailed planning leading to detailed design. These three stages of planning and design lead to the fourth stage of construction following which, we have the management of the constructed facilities. The environment in which the technological system functions, the functioning of the technological system along with man who is involved in the physical system, and the demands placed on the technological system are probabilistic or uncertain. Hence the need for scientific management. Technological systems planning embraces all these stages including the management.

The evaluation relates to several aspects of the impact of the technological system. One is thus the issue of economic evaluation basically deciding the allocation of scarce resources. Over a period of time attempts have been made to make the evaluation more and more comprehensive leading to the social-benefit cost analysis (UNIDo 1972, 1978). Attempts have been made to develop an evaluation approach from the point of view of economic efficiency and equity. Attempts have also been made to take into account the nonlinearities of demands and supply functions, the externalities, the multiple objectives, the inter-and intra-temporal impacts, and the uncertainties.

Besides the socio-economic evaluation we have the environmental impact analysis which tries essentially to take a long term view of the situation in the context of the complex facets of environment and ecology. In view of the large scale and pervasiveness of technology with possible significant changes in environment which may be irreversible and the possibility of resource depletion, it becomes necessary to take this comprehensive view. The third evaluation which has not yet been fully systematised is that of trying to assess and visualise the social impact of technology in terms of values. This is a difficult subject and is still in an initial stage of development.

The central point is that technology has to be developed creatively and scientifically, accessing all technological possibilities and socio-economic-environmental impacts. The development and evaluation are integral activities and have to follow systematically so that, like science, they are reproducible activities.

In view of the complexity of developing technology, a large number of complex alternatives have to be developed and evaluated. This is considerably facilitated by computer-oriented mathematical models and simulation. The value of these models 
and techniques lies in the following: (i) they allow, so to say, 'thought experiments' to be effected with generation of alternatives and evaluation of their performance under different configurations and policies; (ii) they allow decisions on the sensitivity to varying input assumptions and system parameters; (iii) they provide a monitoring device that helps to ensure internal consistency among projects and plans and (iv) they depict qualitative relations among the various factors affecting the supply and demand. It is important to caution that the models do not usually provide the qualitative assessment, but illustrate them schematically (CONES 1981).

The techniques have become possible only due to the availability of modern highspeed computers. Systems analysis does not by any chance negate modern engineering analysis. In fact, these form the input to the systems studies which try to develop alternative options or study the sensitivity.

There is always the danger in the use of models that the numerical results will be taken literally. It must be emphasized that real life issues are extremely complex and not always quantifiable and commensurate. Many simplifications and uncertain assumptions must be made to construct models and a great deal must be simplified and left out of consideration. Judgement alone decides whether some factors are important or whether effects can be separately included, atleast in the first approximation. Models do not negate judgement but complement creativity and judgement by enabling painting over a wide canvas and carrying out the analysis over a wide range. Judgement is also a pre-requisite for modelling, otherwise models can become caricatures of reality.

A variety of techniques are used for modelling such as linear programing, dynamic programing, non-linear programing, queueing theory, graph-theoretic approach, calculus of variations, etc. Each one may be suitable in certain situations. Much work has gone into this area to apply these to different systems and the practitioner has to learn through much detailed study in this area.

One of the reasons why the systems approach has not been adequately applied in real life studies is that examples of applications are generally not available to administration. In this context Rogers (1979) analysed some studies and 22 cases were summarised. The list was not exhaustive and was only meant to provide examples of work that has been used or is in the process of being used and is easily accessible in literature. Some of the studies reported in the book have not been included in the above cases. These cases, given in the appendix, have been summarized under ten separate headings.

(i) Origin and purpose: This is to give some idea of the history of the problem and the purposes of the study.

(ii) Sponsors: Attempts to identify agencies which have sponsored the studies and who may be contacted for further information by persons interested in a particular study.

(iii) Organization of study: How the study was organized. Who did what and where, are important aspects of any systems study.

(iv) Technical team: The details of the technical manpower, leadership and the amount of time from each discipline are given wherever possible.

(v) Structure of analysis: How the original problem was rearranged and structured for analysis.

(vi) Mathematical models: Details of the mathematical models used are given where appropriate.

(vii) Boundaries of study: The real and conceptual scope of the study is given. 
(viii) Evaluation and critique: An evaluation is attempted based on available documentation. Whether the application was used or not for an actual decision is emphasized. (ix) Study results: Based upon the documentation itself, the pertinent results are outlined.

(x) Documentation: Only readily available documentation is listed.

In tables 1 and 2 all these cases have been summarised to show the issues they were concerned with and the systems analysis techniques that were employed. In these tables the studies are ordered by the date of major publication. The reader should be aware that, based upon the reports alone, it is quite difficult to fill in these tables. A fair amount of judgement has to be exercised. This tends to favour the studies that we are familiar with over those we only know from literature.

The most important observation about table 1 is that despite the fact that we have carefully chosen from literature those studies purporting to be the actual case studies performed in, or on, developing countries we feel confident in stating that only 7 out of the 22 studies (or about $1 / 3$ ) have ever been used in making decisions on water planning and management by the sponsoring agencies. Is this a poor batting average?

Table 2, which shows which of the cases use the major systems analysis techniques is, very instructive. Fifteen of the studies (about $2 / 3$ ) used linear programing techniques, none used queueing theory, inventory theory and statistical decision theory and only one used any kind of stochastic model and one used the game theory. There must be some implications here for how one would organize a training programme for professionals interested in applying systems analysis to water planning and management in developing countries.

In concluding this section it should be re-emphasized that the listed case studies are not the only applications made or known to the authors of this report. Numerous other studies are known to have been completed but their documentation is either not available or incomplete. We have chosen to present only those cases which have readily available documentation.

\section{Overview}

An attempt has been made through the studies in this volume to illuminate the systems approach of water resources development. First, the environment and resource availability of water in India and the background of development in a historical context have been given (Chaturvedi 1985a). Formulation of issues for future development, currently proposed policies, a scientific approach to development of the river basin at a national level, and systems approaches for further policy studies have been tried.

Following these general formulations, an issue for a large river basin has been identified and modelled. The particular river basin selected is the Ganga-Brahmaputra basin which is one of the largest basins of the world in hydrological terms. To start with, therefore, a general description of the system follows (Chaturvedi 1985b). Next the approach to planning has been formulated and as a first step a coordinating-screening model is developed to assist in identifying the possible developmental scenarios, taking into account the hydrologic-environmental-economic-interlinkages (Chaturvedi et al 1985). The methodology for trade-offs amongst multi objectives is demonstrated by considering trade offs between different seasons of irrigation and between irrigatton 


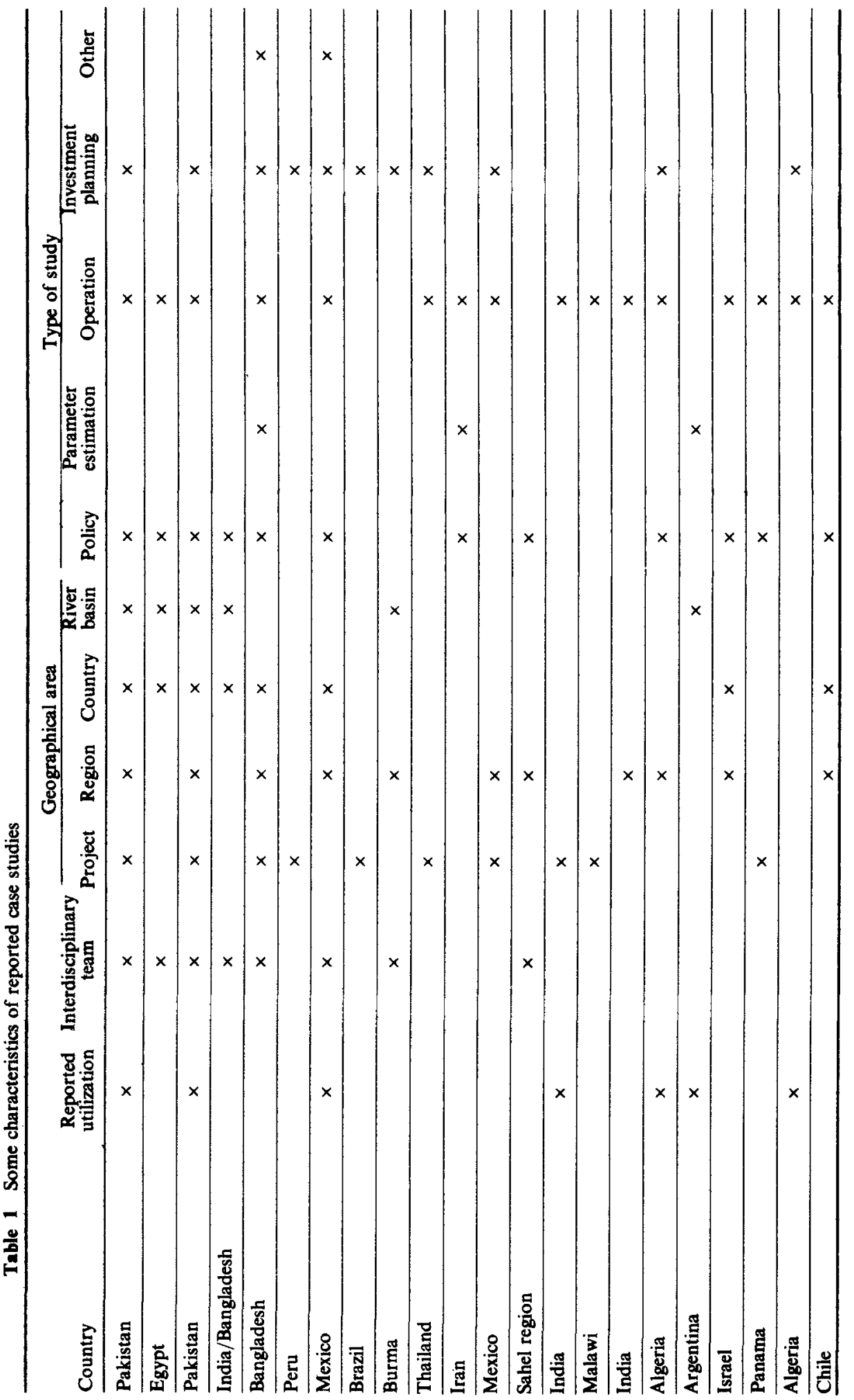


Table 2. The use of systems analysis techniques in the reported case studies

\begin{tabular}{|c|c|c|c|c|c|c|c|c|c|c|c|c|c|c|c|c|c|c|c|c|c|c|}
\hline Case study number & 1 & 2 & 3 & 4 & 5 & 6 & 7 & 8 & 9 & 10 & 11 & 12 & 13 & 14 & 15 & 16 & 17 & 18 & 19 & 20 & 21 & 22 \\
\hline Linear programing & $x$ & $x$ & $x$ & $x$ & $x$ & & $x$ & $x$ & $x$ & & $x$ & $x$ & & $x$ & & $x$ & $x$ & & $x$ & & & $x$ \\
\hline Non-linear programing & $x$ & & & & $x$ & & $\times$ & & & & & & & & & & & & & & & \\
\hline Integer programing & & & & & $x$ & & $x$ & & $x$ & & & & & & & & & & & & & \\
\hline Dynamic programing & & & & & & & & & & & & $x$ & & & $x$ & & & & & & & \\
\hline Goal programing & & $x$ & & & $x$ & & & & & & & & & $x$ & & & $x$ & & & $x$ & & \\
\hline Stochastic programing & & & & & $x$ & & & & & & & & & & & & & & & & & \\
\hline Control theory & & & & & & & & & & & & & & $x$ & & & & & & & & \\
\hline Lagrangean analysis & & & & & & & & & & & & & & & & & & $x$ & & & & \\
\hline Geometric programing & & & & & & & & & & & & & & & & & & & & & $x$ & \\
\hline Queueing theory & & & & & & & & & & & & & & & & & & & & & & \\
\hline Inventory theory & & & & & & & & & & & & & & & & & & & & & & \\
\hline $\begin{array}{l}\text { Statistical decision } \\
\text { theory }\end{array}$ & & & & & & & & & & & & & & & & & & & & & & \\
\hline Multivariate analysis & & & - & & $x$ & & & & & & & & & & & & & & & & & \\
\hline Regression analysis & & & & & $x$ & & $x$ & & & $x$ & & & & & $x$ & & & & & & & \\
\hline Factor analysis & & & & & & & & & & & & & & & & & & & & & & \\
\hline $\begin{array}{l}\text { Principal component } \\
\text { analysis }\end{array}$ & & & & & $x$ & & & & & & & & & & & & & & & & & \\
\hline Simulation & $x$ & & $x$ & & $x$ & $x$ & & & & & $x$ & & & & & & & & & $x$ & & \\
\hline Systems dynamics & & & & & & & & & & & & & & $x$ & & & & & & & & \\
\hline Search techniques & $x$ & & & & & & & & & & & & & & & & & & & & & \\
\hline Game theory & & & & & & & & & & & & & & & & & & & & & & \\
\hline Input/output analysis & & $x$ & & & & & & & & & & & & & & & & & & & & \\
\hline Benefit-cost analysis & $x$ & & $x$ & & $x$ & $x$ & $x$ & $\times$ & $x$ & $x$ & $x$ & & & & & & & & & $x$ & $x$ & \\
\hline
\end{tabular}


and power. This coordinating-screening model is extended to more detailed analysis by dividing the system in terms of hydrological sub-basins (Rogers \& Kung 1985) or administrative-political units of development (Karady \& Rogers 1985). A marginal incremental model has accordingly been formulated. Thus these three studies contribute to an approach for assisting in planning the development of large scale complex river basins.

We have emphasized that the systems approach, first and foremost, is an aid to creative engineering in a scientific manner. In this context we have tried to emphasize the importance of developing all possible technological options. An attempt has been made to develop an unconventional technique of mitigating floods on the one hand and enhancing the water resources on the other through induced groundwater recharge (Revelle \& Lakshminarayana 1985). It is shown that flood flows can be stored by heavy pumping along the perennial rivers for irrigation during the prior low river flow season.

The concept proposed by Revelle was only one of the possible techniques. Other technologies are also possible, such as pumping along non-perennial rivers, and kharif irrigation. Furthermore, these technologies require regional groundwater-aquifer interaction modelling and estimation of optimal groundwater pumping configuration. Therefore, in the following study more refined analysis and in this context three additional alternatives over the basic theme have been proposed and modelled for analysis through a sophisticated regional groundwater simulation-optimization programing model (Chaturvedi \& Srivastava 1985b). This is an important component of the possible technological options in the Ganga Basin. In terms of systems approach principles it demonstrates the opportunity for creative engineering even in conventional areas.

In large scale systems, differences are always likely to arise amongst different uses and users in different parts of the river basin. These could be at the national level or at the international level and an approach to aid in the resolution of these differences through scientific analysis designed to identify optimal systems development in the context of identified mutual interests through bargaining processes has been developed through Game theoretic analysis. This is the pioneering study in the Ganga Basin carried out way back in 1967 by Rogers.

In the development of water resources, generally, emphasis is laid either on the upland water resources for diverse demands or the water quality modelling at the waters edge in terms of the estuary. The fact that a river represents the continuity of the land-water system is very often neglected. For instance, as more and more upland development takes place the flows available at the waters edge are likely to be modified and it would be necessary to take an integrated picture of the upland and the deltaic region estuarine development. In this context a study at the waters edge has been carried out by Rogers. This issue is equally applicable to other river basins of the country.

As we have tried to identify at the outset, systems planning studies require a considerable set of integrated studies. For instance, a detailed analysis of the water demand, particularly of the agricultural demand has to be carried out. While this has not been done for the Ganga Basin, the studies have been carried out for a number of other river basins of the country, such as, Rajasthan Canal (Verma 1985) and the Rangola Irrigation Scheme (Basu et al unpublished). In estimating the water demand and the application principal for irrigation, diverse factors such as economic efficiency, economic equity and/or assurance of food requirement for nutritional considerations 
in a dynamic context of developing agriculture technology are required. Some of these issues have been analysed in the two studies mentioned above.

A variety of problems arise which have a lot of commonality as well as specificity. The commonality is in terms of the integrality of these large scale projects. The specificity stems from the unique configuration of the systems and the specific supply and demand specifications. To illuminate these points several river basins have been studied. These include the two studies for the Indus basin as well as a large component of the Indus basin and the Bhakra dam (Rao \& Ramaseshan 1985a, b), studies of the Cauvery basin (Vedula 1985), Damodar river basin (Sinha \& Rao 1985) and Subernarekha river system (Sinha et al 1985).

A variety of techniques can be used for systems modelling. In the last analysis perhaps simulation will be most convincing and convenient, particularly the stochastic aspects of the development; however, simulating the entire system in the diverse conditions would be extremely time-consuming. A reasonable approach is that a programing model may first be used to find out the range over which simulation studies should be carried out particularly taking into account the stochastic nature of inputs and outputs. This methodologic approach has been tried and applied successfully to the Narmada system (Chaturvedi \& Srivastava 1985a).

\section{Reflections}

Although the present studies do not represent a complete and detailed picture of one particular river basin, the studies taken together, to a large extent cover the diverse problems likely to be encountered in large scale systems planning and we consider that the set of studies would contribute to the art and science of systems planning. We are aware of the shortcomings of the studies reported, which are inherent in the manner in which they were carried out with the essential purpose of developing appreciation and capability in systems analysis amongst some scientists in this field. It is hoped that an integrated study of a real life situation will be carried out at the earliest to contribute to the science and art of the subject and for developing appropriately trained engineers for planning. Water resources development in India is crucial to the development of the country, as emphasized in the 20-point programme of the late Prime Minister as well as in the Planning Documents. A large number of persons are required to carry out this task as sensitive professionals and scientists trained in the best use of the tools of analysis. It is hoped that the present study would contribute to the tremendous challenge posed to the professionals in the country and abroad.

It is unfortunate that much time has been lost. A historic incident may be nostalgically mentioned at the end. Following Rogers study entitled, "A game theory approach to the international aspects of the Ganga Basin", the Indian author was asked by the government in 1968 to carry out the study independently as stated earlier. Following this he was convinced that systems studies of the river basins were required for their efficient development and it was decided that systems studies of the Ganga basin be carried out by the Indian author. A three-month summer school, sponsored by the Ministry of Irrigation was held at the Indian Institute of Technology, Delhi in 1972 to train about 30 officers also in this context. But the activities did not continue and more than a decade has already been lost.

We believe that the development of trained manpower is the most important pre- 
requisite for water resources development and the present volume is dedicated towards this end.

\section{References}

Biswas A K (ed.) Systems approaich to water management (Kogakusha, Tokyo: McGraw Hill)

Chaturvedi M C 1976 Water-second India studies (New Delhi: Macmillan)

Chaturvedi M C 1984 Water resources systems engineering (New Delhi: Tata McGraw Hill) (in press)

Chaturvedi M C 1985a Sadhana 8: 13-38

Chaturvedi M C 1985b Sadhana 8: 73-92

Chaturvedi M C, Rogers P, Kung S L 1985 Sadhana 8: 93-121

Chaturvedi M C, Srivastava D K 1985a Sadhana 8: 311-328

Chaturvedi M C, Srivastava V K 1985b Sadhana 8: 159-177

(CONEs) Committee on Nuclear and Alternative Energy Systems 1979, National Acad. Sci., Washington DC Hall W A, Dracup J A 1970 water resources systems engineering (New York: McGraw Hill)

Karady G, Rogers P 1985 Sadhana 8: 135-145

Klir G J 1969 An approach to general systems theory (New York: Van Nostrand Reinhold)

Meta Systems Inc. 1975 Systems analysis in water resources planning, Water Information Center, Inc.

Rao P S, Ramaseshan S 1985a Sadhana 8: 179-206

Rao P S, Ramaseshan S 1985b Sadhana 8: 207-221

Revelle R, Lakshminarayana V 1985 Sadhana 8: 147-157

Rogers P 1979 The role of systems analysis as a tool in water policy, planning and management, UN Workshop, Water Resources Planning Experiences in a regional and national context, Rome

Rogers P, Kung S L 1985 Sadhana 8: 123-134

Sage A P 1977 Methodology for large-scale systems (New York: McGraw Hill)

Sinha B, Bhatia R, Lahiri S 1985 Sadhana 8: 291-309

Sinha B, Rao P R 1985 Sadhana 8: 273-290

(UNIDO) United National Industrial Development Organisation 1972 Guidelines for project evaluation UN

(UNIDO) United Nations Industrial Development Organisation 1978 Guide to practical project appraisal, United Nations, New York

UN Document E/Conf. 70/29 1977 Report of the UN Water Conference, Mar del Plata, New York, United Nations

Vedula S 1985 Sadhana 8: 223-252

Verma R D 1985 Sadhana 8: 253-271

\section{Appendix}

Case 1 Waterlogging and salinity in the Indus Plain

Origin and purpose To suggest methods to solve waterlogging and salinity in the groundwater of the Indus Plain in West Pakistan. Pakistan President requested help from President Kennedy.

Sponsor White House and Government of Pakistan

Organization of study Highlevel panel for one year period. Most of analysis performed at various locations in the Us. Report written by Professor Revelle and Harvard University group who performed the systems analysis.

Technical team Panel drawn from Government and universities consisting of scientists, engineers, agronomists and economists.

Structure of analysis To make a detailed investigation of possible approaches to the waterlogging and salinity problems. Problem broken down into several pieces, solution undertaken by different groups and then integrated at the end by a core group of the panel. 
Mathematical

models

Boundaries of study

area

Study results

Evaluation and critique

Documentation
Linear and quadratic programing, simulation models for groundwater movement and mixing.

The basin of the Indus river and its major tributaries in Pakistan (then West Pakistan).

Showed that the waterlogging and salinity could be most effectively controlled through vertical drainage using tubewells. In addition, it demonstrated how this drainage water could be used to further develop irrigation.

A benchmark study using systems analysis in water management. Many new models were developed. Even though some of the detailed findings and recommendations were later not upheld, the report has been the fundamental policy document of the development of irrigation in Pakistan.

White House-Department of Interior Panel on Waterlogging and Salinity in West Pakistan, Report on Land and Water Development in the Indus Plain, White House, Washington, D.C., Jan. 1964. Dorfman R, Revelle R, Thomas H A Jr 1965. Pakistan Dev. Rev., 5: 331-372 Fiering M B 1965 Water Resources Res. 1: 41-61.

Case 2 Use of Aswan High Dam in Egypt for hydropower and irrigation

Origin and purpose

\section{Sponsor}

Organization of study

Technical team

Structure of analysis

Mathematical models

Boundaries of study

Study results

Evaluation and critique

Documentation
Studies of operation of the new Aswan High dam. Particular emphasis on the resolution of conflicts between energy and irrigation uses.

Ministry of the Aswan High dam, Egypt and Ford Foundation, Cairo.

Performed by Center for Population Studies, Harvard University. Small team; most of work performed in the Us. Period 1 year.

2 engineers, 1 economist, 1 regional planner and 1 population scientist on a part-time basis.

To establish the ultimate resource potential of the Nile in Egypt.

Goal programing (linear programing) use of $1 / 0$ models

Nile river basin within Egypt

Established the degree of complementarity between conflicting uses for power and irrigation. Identified possible developments of downstream underground storage to achieve $100 \%$ complementarity of water use.

An early application of goal programing to water management. Raised interesting research questions about alternative investments. Was not continued because of lack of follow up by the government departments.

Thomas H A Jr, Revelle R 1966 Manage. Sci. 12B: 296-311

\section{Case 3 Water and power resources of West Pakistan}

Origin and purpose

Sponsor

Organization of study

Technical team

Structure of analysis
Part of the Indus Water Treaty. A sector plan for water and power for Pakistan was needed to evaluate the further development of the system, particularly, the decision to build Tarbela dam.

Government of Pakistan, World Bank.

Bank provided an interdisciplinary group to coordinate a series of specialist studies which were then integrated into a coherent study by the Bank.

Cordinating group mainly administrators, and development economists, consultants from many other disciplines.

A macroeconomic model was made to coordinate separate studies of the power 
and agricultural sectors. Agricultural sector chooses water technology as well as cropping pattern via a linear programing model. The power model simulates the detailed functioning of the electrical energy system.

Mathematical models

Boundaries of study

Study results

Evaluation and critique

Documentation
Linear programing models of the agricultural sector and simulation models for the hydrology and the power sector.

Province of West Pakistan

Confirmed the strategy of groundwater exploitation and the timing of the construction of Tarbela dam

A large and complex study. Extremely well carried out. This is probably the landmark study of the 1960's. In addition to the Bank and the consultants work, the officials of the Government of Pakistan were deeply involved in the interpretation of the results. The cost of the overall study which is not reported in the literature must have been substantial (in millions of us dollars).

Lieftinck P R, Sadove A R, Creyke T C 1969 Water and power resources of West Pakistan: A study in sector planning, 3 vols., (Baltimore: Johns Hopkins).

Case 4 Resource potential of the lower Ganga-Brahmaputra basin

Origin and purpose

Sponsors

Organization of study

Technical team

Structure of analysis

\section{Mathematical models}

Boundaries of study area

Study results

Evaluation and critique

Documentation
Study to find the resource development potential in the Lower GangaBrahmaputra Basin and the costs and benefits of international cooperation between the riparian states.

Ford Foundation and Harvard University with the collaboration of the Governments of India and Pakistan.

Performed as a desk study by a small team at the Center for Population Studies, Harvard University.

One engineer and one economist part time for one year.

To search for the ultimate development potential of the Lower Basin of the Ganga-Brahmaputra rivers for irrigation, flood protection, hydropower, navigation and water supply. To examine the costs and benefits of international cooperation on the ultimate development.

Game theory, Linear Programing (720 variables and 450 constraints)

Basins of the Ganga and Brahmaputra rivers including Bangladesh and Nepal but not China or the Indian states further upstream than Bihar.

The study showed that the problem was a classical "prisoners-dilemma" game problem. The benefits for cooperation were large (about $25 \%$ of total) but not overwhelming.

Innovative approach to this class of problem. The data used were, however, very unreliable and the study was never acceptable to the Government of India for further elaboration although the Government of Pakistan supported (with UNDP support) elaboration of the East Bengal part of the study area.

Rogers P 1969 Water Resources Res. 5: 749-760.

Case 5 Land water and power studies for Bangladesh

Origin and purpose Part of a proposed larger study of the entire Ganga and Brahmaputra basins. This study attempted to look at the integrated development of land, water and power in East Bengal from 1969 to the year 2000.

Sponsors Government of Pakistan (later Government of Bangladesh), uN Development Program with the International Bank for Reconstruction and Development as their executing agents. 
Organization of study

Technical team

Structure of analysis

Mathematical
models

Boundaries of study

Study results

Evaluation and critique

Documentation
Model work was carried out at the Harvard University Center for Population Studies. Extensive collection of secondary data in the field.

Small team of 2-3 engineers, 2 economists, 1 geographer and 1 population scientist.

The emphasis was on the human ecology of the region. The analysis started with an elaborate population prediction model which responded to the rates of economic development.

A variety of mathematical programing and simulation models were made. The major model was a two level mixed integerquadratic programing model of the entire agricultural sector. These models had 100 integer and 1300 continuous variables and 1000 constraints.

Entire region of Bangladesh excluding the Chittagong hill tracts.

The studies indicated a water resources development strategy relying on small pumps and tubewells in the next decade. While indicatung self sufficiency in food as a possibility for Bangladesh the models indicated severe energy/fertilizer shortages in the near future.

An ambitious study integrating population, land, water and energy. There were too many models made with consequent integration problems. The hydrological constraints were explored in great detail. Due to the change of governments the transfer of the model studies application by the various government agencies in Bangladesh has not yet (1979) taken place 7 years after the study was completed.

Rogers P et al 1972 Bangladesh land water and power studies Draft Report, Harvard University Center for Population Studies; Rogers P, Smith D V 1970 Am. J. Agric. Econ. 52: 13-24; Rogers P 1974 ITCC Rev. 111: 110-119.

Case 6 Project selections and macroeconomic objectives: A methodology applied to Peruvian irrigation projects

Origin and purpose

Sponsors

Organization of study

Technical teams

Structure of analysis Mathematical
models

Boundaries of study

Study results

Evaluation and critique

Documentation
An attempt to bridge the gap between macroeconomic objectives and detailed project investment criteria. The methodology was tested on 11 public irrigation projects in Peru.

Not mentioned.

Details not given. Eleven projects were selected on the basis of completed feasibility reports, covering a range of project sizes, and geographical zones.

Detals not given.

Four classes of investment criteria were investigated in addition to a fifth method putting together the income balance of payments, and the employment objectives.

No formal models used. Simple national preference function was hypothesized and the project selection rankings simulated under a variety of weights on the objectives.

All irrigation projects within the national boundary.

The study showed that the ranking of the projects was very insensitive to quite large variations in the weights on goals.

The study is a good example of the combined use of various economic and social criteria for choosing irrigation projects. There were no constraints on resource use nor were there any interactions either economic or hydrological allowed between the projects. Hence, a large part of the "systems approach" could not be applied.

McGaughey E, Thorbeke E 1972 Am. J. Agric Econ. 54: 32-40. 
Case 7 Programing models of Mexican agriculture

Origin and purpose These studies were part of an integrated multi-level national planning model for Mexico. The irrigation models were just one part of the overall study.

Sponsors

Organization of study International Bank for Reconstruction and Development (IBRD) (Development Research Center).

Technical team

Mainly carried out in Washington, DC by a group of agricultural and development economists with collaboration on data from various Mexican government agencies.

Structure of analysis

Exact details not given, mainly economists.

A very elaborate multi-level structure was given to the study. Each of the sectors (agriculture and power) had to choose its best investment schedule subject to resource availabilities predicted by a multi sector input/output model.

Mathematical model Variety of simulation, integer programing and linear and quadratic programing models. Main model was solved as a linear program (with 2,345 variables and 1,500 constraints).

Boundaries of study All the agricultural regions of Mexico.

area

Study results

Elaborate projections detailing expected regional demand for water, crop production, and the market equilibrium prices for the products were made. These were also shown to be consistent with expected macroeconomic growth in the other major economic sectors.

Evaluation and critique

The study received the Lanchester Prize of the Operations Research Society of America for the best or publication of 1976. The study is very innovative in the handling of some of the economic features such as endogenous prices and in the models to check sectoral consistency. The multi-level models only worked in an ad hoc way and the resource constraints particularly the water constraints, are handled casually. The authors claim that the models are in use by the Ministry of the Presidency in Mexico. There is, however, some dispute whether the water agencies are indeed using the models to guide investments.

Documentation

Goreux L, Manne A S 1973 Multi-level planning: Case studies in Mexico (Amsterdam: North Holland); Bassaco L M, Norton R D, Silas J S 1974 Water Resources Res. 10: 1071-1079.

Case 8 Cost-benefit analysis of irrigation projects in Northeastern Brazil

Origin and study

The study examined irrigation projects in Northeastern Brazil which had been found acceptable by the Ministry of Interior and re-evaluated them using an empirically estimated shadow price on labour.

Sponsor

Organization of study

Brazilian Planning Ministry.

Technical team

Carried out by Cline as Visiting Professor in the Planning Ministry with the help of Tahal for data and engineering advice.

Structure of analysis

Development economist aided by engineering consultant.

Reviewed 24 major projects out of a possible 56 available. Recomputed benefit cost ratios with shadow prices on labour and optimal cropping patterns obtained from a linear programing model.

Mathematical Linear programing (119 constraints, number of variables not given).

models

Boundaries of study Northeast Brazil.

area 
Study results

Evaluation and critique

Documentation
Of the 24 projects studied only 14 had a benefit-cost ratio greater than unity when the shadow prices and optimal cropping were applied. Only about $55 \%$ of the total predicted area could, therefore, be justified on the revised economic basis.

A unique study. It clearly demonstrates an effective way to generate the shadow prices to evaluate projects in the water sector.

Cline W R 1973 Am. J. Agric. Econ. 55: 622-627.

Case 9 Mu river valley multipurpose scheme, Burma

Origin and purpose Irrigation feasibility study for the Mu river valley multipurpose scheme, also considered hydro power production. Study area 1,000,000 acres* with 8 possible dam/reservoir alternatives and pumped and gravity flow irrigation systems considered.

Sponsors

Burmese Government and the United Nations.

Organization of study

Details not reported.

Technical team

Booz, Allen, and Hamilton and Italconsult

Structure of analysis

Both conventional and systems analysis methods were used. Choose that system of dams, reservoir, river diversion points and major irrigation canals and determine which crops to grow, where, when and in what quantities in order to maximize the internal rate of return of project over its first 50 -year period.

Mathematical model Mixed integer programing (750 continuous variables, 50 integer variables, and 250 constraints)

Boundaries of study Basins of the $\mathrm{Mu}$, Chindwin and Irrawaddy.

Study results

The systems analysis studies chose a smaller capital cost, $\$ 142$ instead of $\$ 179$ million with the same level of steady state net annual benefits but with an $11 \%$ internal rate of return rather than $9 \%$. The developed area also declined from 5 lakh to 3 lakh acres. Acceptance of results by sponsors not reported.

Evaluation and critique Valuable exercise in comparing conventional methods with system analysis methods. Some problems with completing the integer programing algorithm.

Documentation

Rose C J 1973 Manage. Sci., 20: 423-438.

Case 10 Rural water supply program effectiveness in Thailand

Origin and purpose

Sponsor

Organization of study

Technical team

Structure of analysis

Mathematical models
To improve the methodology of impact evaluation of rural water supplies looking ex post at a variety of completed projects.

Ministry of Public Health, Thailand, USAID and the Asian Institute of Technology.

79 rural water supply plants were evaluated in Northeast Thailand. 3 man-years went into visiting each of the villages and rural areas where the plants were located. Six typical village plants were studied in detail.

Department of Environmental Engineering, Asian Institute of Technology (AIT), Bangkok.

Systems analysis was used mainly to structure the problem being studied.

Only simple statistical models were utilized.

$*_{1}$ acre $=0-405$ ha 
Boundaries of study Northeast region, Thailand.

Study results

Showed the need for broader impact analysis than those based entirely upon conventional benefit/cost analysis.

Evaluation and critique

This study is a "soft" use of systems analysis. The systems approach being used to "structure the problem" to be analysed, the analysis itself being rather trivial in nature.

Documentation

Trankel R J 1974 Water Resources Res. 10: 163-169.

\section{Case 11 Pricing irrigation water in Iran}

Origin and purpose

Sponsor

Organization of

Technical team

Structure of analysis

Mathematical

models

Study results

Evaluation and critique

Documentation study

In 1968 Iran nationalized water supplies. The study is part of a methodology for the government to set water charges for irrigation.

Industrial Management Institute, Tehran, Iran

Joint study by groups at the Industrial Management Institute. Organizational details not given.

\section{Economists}

The study was based upon an exploration of classical economic theories of public sector investments.

A simulation model was derived to simulate alternative pricing rules.

A framework for evaluating irrigation water pricing was derived based upon ability to pay, costs of supplying water and covering reimbursable costs.

Reported work is based upon theoretical consideration only. No empirical tests of the model are reported. The system appears to be reasonably easy to implement.

Gardner B D, Madhi Y, Partovi S, Martega H, Mehdi S 1974 Water Resources Res. 10. $1080-1084$.

Case 12 Groundwater management and salinity control: A case study

Origin and purpose

The primary policy issues in coastal groundwater development are the rate of groundwater use, allocation between irrigation and leaching, and the selection of crops.

Sponsor

Resources for the Future

Organization of study

Technical team

Details of organization not reported.

Structure of analysis

1 resource economist

Study looked for the optimal rate of exploitation of the scarce groundwater resource when consideration is given to future costs and benefits including the impact of salt-water intrusion.

Mathematical

models

Dynamic programing and parametric linear programing

Boundaries of study area

Study results

Sahvarsal irrigation district, Sonora, Mexico.

The groundwater stock should be mined at a rapid rate for the first decade. The leaching rate should be between $33 \%$ and $43 \%$. Soil salinity is maintained below $6 \mathrm{mmho} / \mathrm{cm}$ over the entire decision horizon of 30 years. Substantial changes in the current cropping patterns are recommended. Salt water intrusion is increased by $8 \mathrm{~km}$.

Evaluation and critique
A clever combination of linear and dynamic programing. The author expressed a major concern regarding the availability of sufficient data to use this 
Documentation

method. No indication if it has been used by the Mexican government to evaluate its proposed major interbasin water transfer.

McFarland J W 1975 Am. J. Agric. Econ. 57: 457-462.

Case 13 Long term policies for the recovery of the Sahel

Origin and purpose An attempt to study the 1969-72 drought in the Sahel of West Central Africa and look to long term policies for recovery and restoration.

\section{Sponsor}

Organization of study

Technical team

Structure of analysis

Mathematical

models

Boundaries of study

area

Study results

Evaluation and critique

Documentation
USAID

Professors and students at the MIT Center for Policy Alternatives organized around the use of Forrester models. Details not reported.

Multi-disciplinary team, predominantly engineers.

To analyze the historical pattern of animal husbandry and use them to predict future behaviour under a variety of management scenarios.

Systems dynamics simulation models used.

Pastoral zone of Niger north of Tahoua

Sudden collapse of the human and animal population were predicted if present policies were pursued. The proposed solution was to concentrate on range conservation with the cattle population being adjusted each year to the carrying capacity of the range.

The approach is innovative but the models are highly aggregated. The "sudden collapse" syndrome of thse types of models is suspicious. The study did not address practical implementation problems.

Picardi A C, Seifert W W 1976 Technol. Rev. 78(6): 42-52.

Case 14 Joint operation of Bhakra reservoir for power and irrigation

Origin and purpose

Sponsor

Organization

of study

Technical team

Structure of analysis

Mathematical models

Boundaries of study

Study results

Evaluation and critique
An attempt to view the operations of the Bhakra Management Board from the point of view of goal programing.

Indian Institute of Technology (IIT), Kanpur.

This was a desk study carried out at IIT Kanpur and Harvard University as a PhD thesis.

1 civil engineer and his advisor (a hydrologist).

The studies focussed on the detailed operation of the system starting in September until February. The models were arranged to compare actual operations with hypothetical ones.

Goal programing model (200 variables and 150 constraints) and control model.

Bhakra dam and reservoir.

Study showed that the current operations of the dam could be changed slightly to increase both the amounts of energy produced and the irrigation water available.

This is an extremely simple and elegant study. Since its completion the Bhakra Management Board has been considering testing it out to modify their release rules. 
Documentation

Rao P S 1977 Multiobjective analysis of Punjab water resources system, Ph.D. Thesis, Indian Institute of Technology, Kanpur, India.

Rogers P, Rao P S, Ramaseshan S 1976 Multiobjective analysis for planning and operations of water resource systems: Some examples from India, Presented at the 1976 Joint Automatic Control Conference, Purdue University, Lafayette, Indiana, mimeo.

Case 15 Irrigation system operating policies for mature tea in Malawi

Origin and purpose

Sponsor

Organization

of study

Technical team

Structure of analysis

Mathematical models

Study results

Evaluation and critique

Documentation
To appraise the economic return to investments in irrigation systems for mature tea in Malawi. To test the hypothesis that distribution of soil moisture within the root zone is an important determinant of the irrigation response of tea.

Tea Research Foundation of Central Africa, Overseas Development Administration (UK), and Tea Research Foundation.

Details not given.

1 agricultural economist.

The yield of tea as a function of soil moisture was established by conventional agronomic methods. This was then used to evaluate the objective function of the major optimizing model.

Regression models and Dynamic Programing.

Optimal irrigation policy does not attempt to refill the whole root zone to field capacity.

Not many systems studies are available for non-cereal crops. This study is an interesting combination of empirical data generation and theoretical modelling.

Palmer-Jones R W 1977 Water Resources Res. 13: 1-7.

\section{Case 16 Optimal cropping pattern for a basin in India}

Origin and purpose

Sponsor

Organization of study

Technical teams

Structure of analysis

Mathematical

model

Boundaries of study

Study results
Part of a larger study of the conjunctive use of ground and surface water in the Punjab state of India.

Punjab Irrigation Department.

Joint study between Punjab Irrigation Department and IITs Delhi and Kanpur. Data provided by the Irrigation Department engineers to university teams.

Engineers.

A study of the optimal cropping pattern and water release from canals and tubeweils. The object is to determine the amount of seasonal water releases from the two sources during a 1-year period of operation.

Linear programing (size not given).

\section{Ravi Doab tract in Punjab}

Canals are used to maximum capacity in all months. Tubewells are used to maximum capacity only in October. Sensitivity analysis was carried out on tubewell capacity, area available for irrigation, and the operation costs for canals and tubewells. 
Evaluation and critique

Documentation
A empirical test of some models already in literature. There are some problems with the crop responses as cotton does not enter the solution at all and an increase in available irrigable area reduces the area sown with rice. These may be artifacts of the linear program.

Lakshminarayana V, Rajagopalan S P 1977 J. Irrig. Drainage Div. ASCE 103: 53-70.

Case 17 An application of interactive multiobjective water resource planning in Algeria

Origin and purpose

Sponsor

Organization of study

Technical team

Structure of analysis

Mathematical models

Study results

Evaluation and critique

Documentation
As part of the planning for large scale diversion of water for irrigation away from the coastal plain in Algeria the need for appropriate planning objective arose. This study, which is part of the larger study, specifically addresses the setting of planning goals.

Ministry of Industry, Government of Algeria.

Designed as an interactive study in which goal programing produces sets of solutions which government officials discuss and accept or reject. This is then the basis for another iteration in which the objectives are slightly modified in response to the governments initial reaction.

Details not given. Predominantly engineers.

The analysis was arranged specifically to allow for administrative interaction throughout the study. Explicit use of political judgements were made use of throughout the study.

Linear goal programing (the STEM method).

Details not given. During the iterative process new objectives and new constraints were identified and the models modified. Trade-offs were made among the targets for irrigation, the yield reliability, and the costs of the projects.

This case is unusual in that it reports the use of socio-political evaluation during the study itself. Work on the engineering designs based upon this study is now under way.

Loucks D P 1977 Interfaces 8: 70-75.

Case 18 Optimization method for estimating aquifer parameters

Origin and purpose

Sponsor

Technical team

Structure of analysis

Mathematical models

Boundaries of study area

Study results

Evaluation and critique
Future development of aquifers requires reliable calibration of transmissivity and storage coefficients. Several large groundwater basins in Argentina needed quantitative evaluation. Scarcity of data required good calibration of the groundwater models.

United Nations, Office of Technical Cooperation, Government of Argentina. Groundwater hydrologists.

The appraoch taken was to assume a model and optimize the fit of this model to the observed data. In doing so, the optitum estimates for the aquifer characteristics are generated.

Lagrangean analysis (unconstrained optimization)

Tulum Valley $(80,000 \mathrm{ha})$, and Mendoza Valley (100,000 ha), Argentina.

Model calibrated extremely well within estimated field parameters.

First developing country application of these methods. The result shows the power of those techniques to argument poor quality data bases. 
Documentation

Navarro A 1977 Water Resources Res. 13: 935-939.

\section{Case 19 Water shortage in Israel}

Origin and purpose

Sponsors

Organization of study

Technical team

Structure of analysis

Mathematical models

Boundaries of study

Study results

Evaluation and critique

Documentation
Israel faces limited water supply and increasing demands. Study analyses the policy of reducing allocktions of water to irrigation.

Ministry of Agriculture, Israel.

Details not given.

Agricultural economists.

In each of the regions the economic impact of reducing water quotas was derived using an optimizing model which was constrained by water constraints. These constraints were then varied parametically.

Linear programing for each of 16 regions.

Israel.

Shows that response of income to water reduction is "inelastic", $10 \%, 20 \%$ or $30 \%$ reduction in water quotas to irrigation will result in $6 \%, 12 \%$ or $18 \%$ reduction in farm income if no technological change is assumed. If technological changes are assumed then reductions in agricultural income will be $1 \%, 7 \%$ and $12 \%$.

A very simple yet elegant approach to a very serious problem (agriculture uses $70 \%$ of total water supply). No indication that the policy assumptions will be followed.

Gisser M, Pokaryles S 1977 Water Resources Res. 13: 865-872.

Care 20 The economic value of the Panama Canal

Origin and purpose

Sponsor

Organization of Study

Technical team

Structure of analysis

Mathematical models

Boundaries of study

Study results

Evaluation and critique

Documentation
An attempt to assess the worldwide economic consequences of the Panama Canal becoming unavailable. This is part of the analysis of the costs of the new Panama Canal treaty between the us and Panama.

Details not given.

Details not given.

Commodity Transportation and Development Laboratory, Massachusetts Institute of Technology (MIT).

A variety of plausible alternative scenarios were assumed and the economic consequences of them evaluated.

Simulation and multiobjective analysis.

World ocean trading system.

Shows the net present economic value to the world of US\$6 billion and to the US of $\$ 1.6$ billion.

Despite some heroic assumptions in the analysis the results are probably sufficient to arrive at the nature of the trade-offs which could potentially face the us.

Gibbs S R Water Resources Research 14: 185-189. 
Case 21 Algerian agricultural water conveyance system

Origin and

purpose

Sponsors

Organization

of study

Technical team

Structure of analysis

Mathematical models

Boundaries of study area

Study results

Evaluation and critique

Documentation
Engineering feasibility for transporting water to the inland Setif region of Algeria from several rivers flowing north into the Mediterranean. 50,000 hectares are expected to be brought under irrigation.

\section{Algerian Government}

Details not reported.

Bechtel Inc., San Francisco, details not reported.

To select the most efficient design parameters for a $30 \mathrm{~km}$ water transport pipeline.

Geometric programing.

From coastal reservoir to inland irrigation system.

Savings of over $\$ 1$ million per year were predicted using the parameters selected over the best "hand" designed system. Project results accepted by Algerian Government and are now in detailed engineering design phase.

The system was narrowly defined and only the costs considered (cost minization objective function), however, the predicted savings are substantial.

Wyman F P 1978 Interfaces 8: 1-6.

Case 22 Water utilization and reallocation in Chile

Origin and purpose

Sponsor

Organization of study

Technical team

Structure of analysis

Mathematical model

Boundaries of study area

Study area results

Evaluation and critique

Documentation
1967 Water Code requires equalization of water rights per hectare in each homogeneous farming area. This study was made to assess the income redistribution impacts that would result from such equalization.

Ford Foundation and National Institute of Agricultural Research of Chile.

Details not given

2 agricultural economists.

118 farms of 5 hectares and larger were surveyed and broken down into 3 categories. One typical farm from each category was modelled using a deterministic linear programing model.

Linear programing at farm level (size not given).

Pirque Valley in Central Chile.

Equality pursued on a per hectare basis will result in economic inefficiency and a worsened income distribution.

An elegant approach to the problem of equity in irrigation water allocation. However, conclusions are based upon a relatively small sample of farms. No indication that the results have been utilized by the Government.

Parks L L, Hansen D E 1978 Am. J. Agric. Econ. 59: 207-213. 